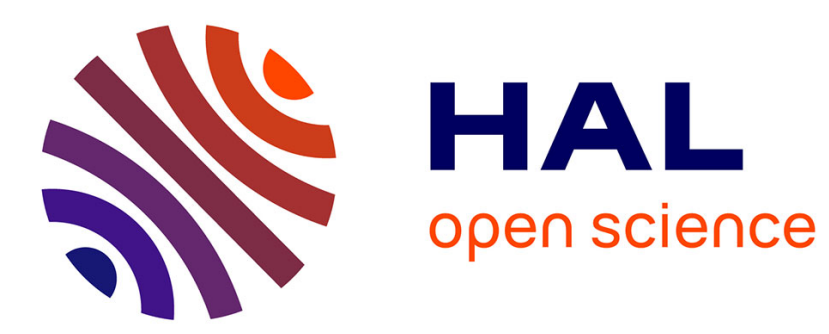

\title{
Between social awareness and productivity, results of a survey about real-time microblogging
}

\author{
A. Joly, Pierre Maret, Johann Daigremont
}

\section{To cite this version:}

A. Joly, Pierre Maret, Johann Daigremont. Between social awareness and productivity, results of a survey about real-time microblogging. First Monday, 2010, http://firstmonday.org. ujm-00534530

\section{HAL Id: ujm-00534530}

\section{https://hal-ujm.archives-ouvertes.fr/ujm-00534530}

Submitted on 9 Nov 2010

HAL is a multi-disciplinary open access archive for the deposit and dissemination of scientific research documents, whether they are published or not. The documents may come from teaching and research institutions in France or abroad, or from public or private research centers.
L'archive ouverte pluridisciplinaire HAL, est destinée au dépôt et à la diffusion de documents scientifiques de niveau recherche, publiés ou non, émanant des établissements d'enseignement et de recherche français ou étrangers, des laboratoires publics ou privés. 
Between social awareness and productivity, results of a survey about real-time microblogging by Adrien Joly, Pierre Maret, Johann Daigremont

\begin{abstract}
:
In April 2010, we conducted a survey towards 256 users of real-time microblogging platforms, mostly Twitter users, in order to analyze the usage of those platforms and evaluate the induced cognitive impact. In this article, after reporting and discussing the results of this survey, we identify opportunities for improvement towards reducing information overload and frequent disruptions. Then, we propose a novel approach for filtering status updates from real-time microblogging platforms, based on contextual relevance between their authors.
\end{abstract}

\title{
Contents
}

Introduction

Results of the survey

Filtering mechanisms: challenges, solutions and opportunities

Our proposal: contextual filtering of status updates

Conclusion

Acknowledgment

\section{Introduction}


After forums, blogs, instant messaging and other Internet-based communication platforms, Microblogging has become a new communication paradigm on the Internet, enabling large communities to keep in touch, improving awareness and collaboration between people, and facilitating new contacts. Since the launch of Twitter (http://www.twitter.com/) in October 2006, users have been invited to share concise status updates regularly about their activities, current interests and opinions, for their followers [java_we_2007]. Twitter made it possible to send such updates from anywhere by SMS, and to be notified of updates sent by followed twitter users through a personalized feed but also by SMS, allowing the use of any mobile phone without requiring access to the Internet. Users adopted this platform through various unexpected usages: to share their news, moods, ideas and jokes, to ask for advice, to relay news and hazardous events they witnessed [mischaud_twitter:_2007] (by re-tweeting the status update from their original author), and even to enable fluid and transparent client-to-business communication.

Microblogging platforms can help to virtually increase the number of individuals with whom a stable interpersonal relationship can be maintained. Known as the Dunbar number [dunbar_co-evolution_1993], observed values of this number can vary between 100 and 200 for humans. Indeed, computer-supported social networking platforms (including microblogging platforms) can be used to overcome cognitive limits of one's social memory, and therefore to be potentially able to keep in touch with more than 200 people at once. Overcoming this limit can expand people's ability to solve problems, by connecting with more weak ties, those unfamiliar or remote acquaintances that are intimate enough to want to help out.

Nevertheless, microblogging platforms rely on subscription to specific people's social feeds. This characteristic implies that reading all the status updates from subscribed social feeds is costly, in terms of attention, as their number increase. Furthermore, users can be notified of new status updates from their subscribed feeds in real time, causing frequent interruptions. Therefore, the additional cognitive load 
induced by following the status updates of too many people also induces harmful effects. As reported in [roda_atgentive_2006], whereas interruptions can sometimes facilitate performance of people's ongoing tasks [speier_effects_2003], they may also generate stress [bailey_effects_2001,zijlstra_temporal_1999] and compromise the performance of the primary task [franke_recovering_2002, mcfarlane_scope_2002, nagata_multitasking_2003, speier_effects_2003], caused by increased load on attention and memory [gillie_what_1989]. According to [miyata_psychological_1986], consuming unexpected messages (in our case: status updates) can be both beneficial and disruptive. They recommended that users can control the trade-off, to be able to accept diverted or not, depending on the context.

In this article, after reporting and discussing the results of a survey we conducted on usage of microblogging platforms, we identify opportunities for improvement towards reducing information overload and frequent disruptions. Then, we propose a novel approach for filtering status updates from real-time microblogging platforms, based on contextual relevance between their authors.

\section{Results of the survey}

In April 2010, we conducted a survey towards 256 users of real-time microblogging platforms, mostly Twitter users, in order to analyze the usage of those platforms and evaluate the induced cognitive impact. 


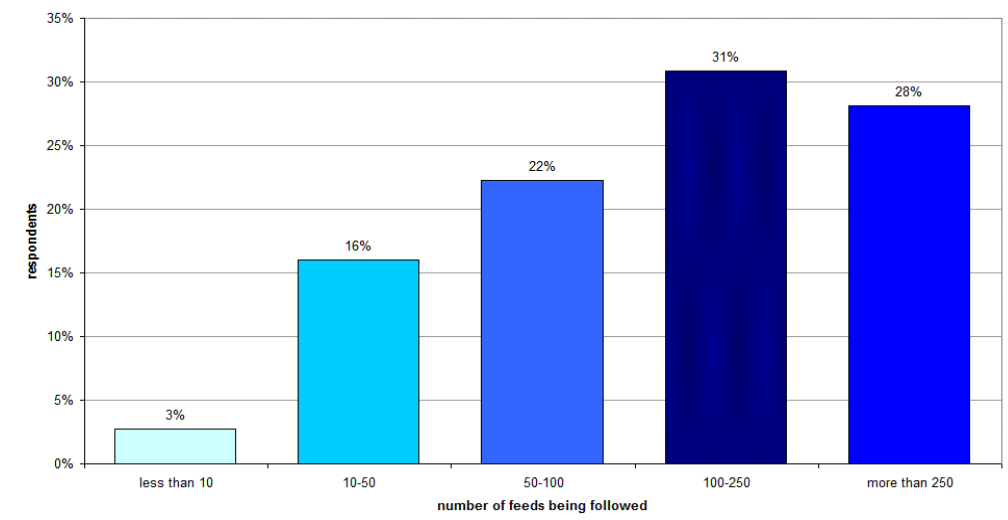

As seen on the distribution chart above, most respondents (31\%) follow between 100 and 250 people feeds.

The second category of respondents (28\%) follow more than 250 feeds, which is much higher than the Dunbar number (i.e. the maximum number of people one can naturally maintain a stable relationship with).

Insert 2.gif Here, Caption = Uses of microblogging

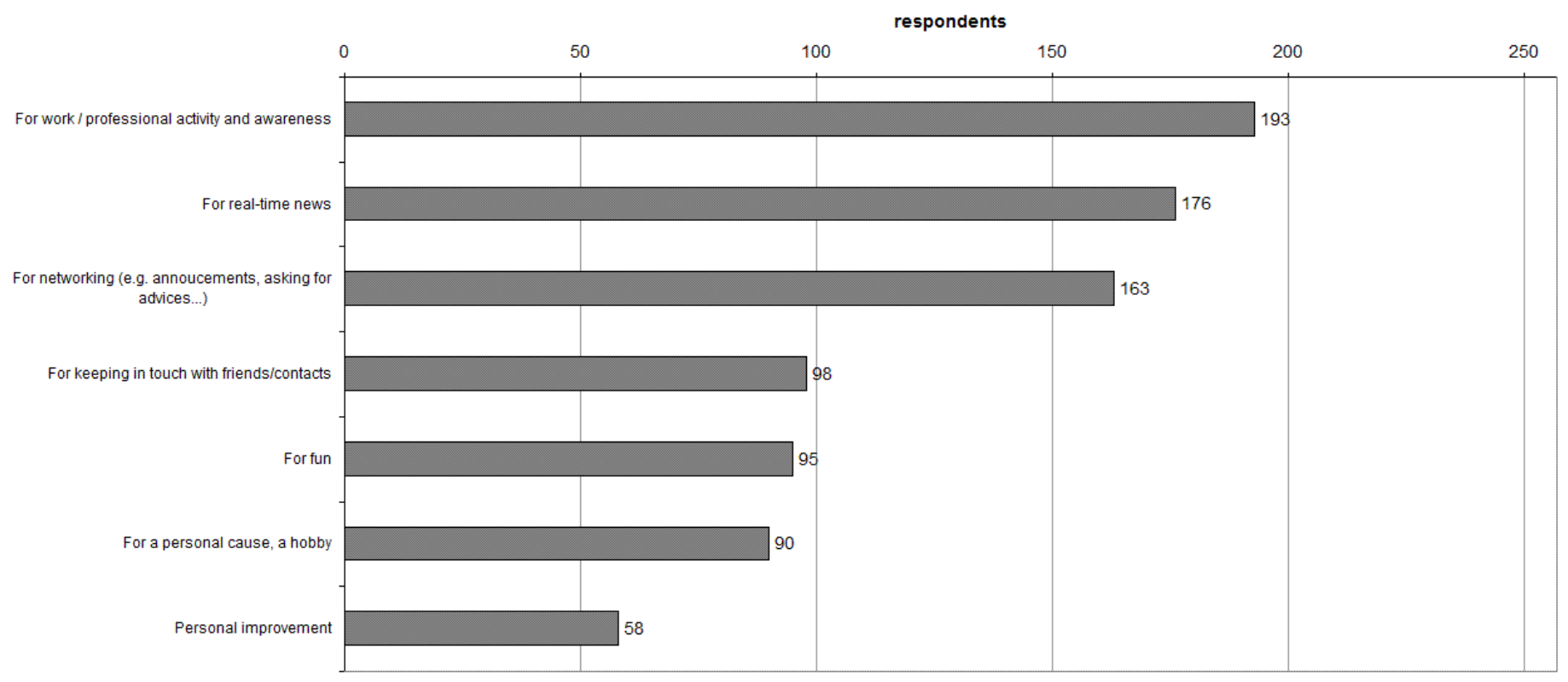


Figure 2 reveals that $75 \%$ of respondents use microblogging platforms for their professional activity, $69 \%$ use those for keeping up with news, and 64\% leverage the six degrees of separation effect for networking (i.e. making announcements, or ask for advice from their contacts). Personal and fun usage of microblogs is lowly represented (23\% to $38 \%$ ), at least by the respondents of this survey.

Insert 3.gif Here, Caption = Usefulness of microblog updates: for current activities (left), and for longer-term goals (right)
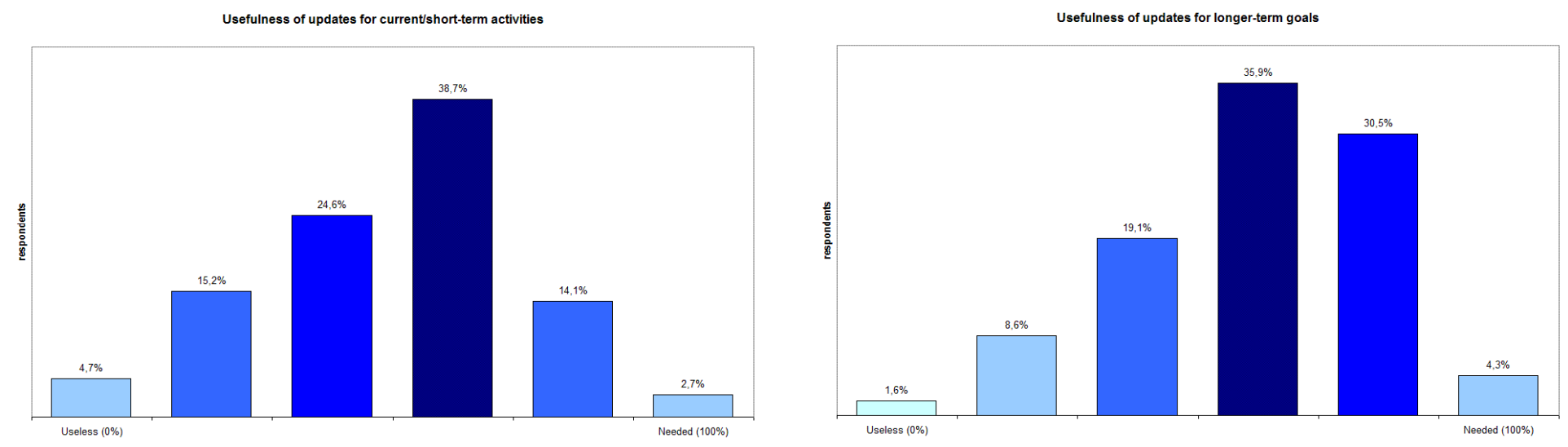

On a 6-rank scale between 0 and 5, most respondents (between 35.9\% and 38.7\%) gave a medium-high rate of 3 to evaluate the usefulness they perceive over all the updates they read, as depicted on Figure 3. However, we observe that usefulness is rated slightly higher for longer-term goals (4 being the second most given rate, with $30.5 \%$ ) than for current activities ( 2 being the second most given rate, with $24.6 \%$ ). This can support the hypothesis that, in most cases, new real-time updates should rather not interrupt users in their current activities, as many updates show little usefulness for this activity. 


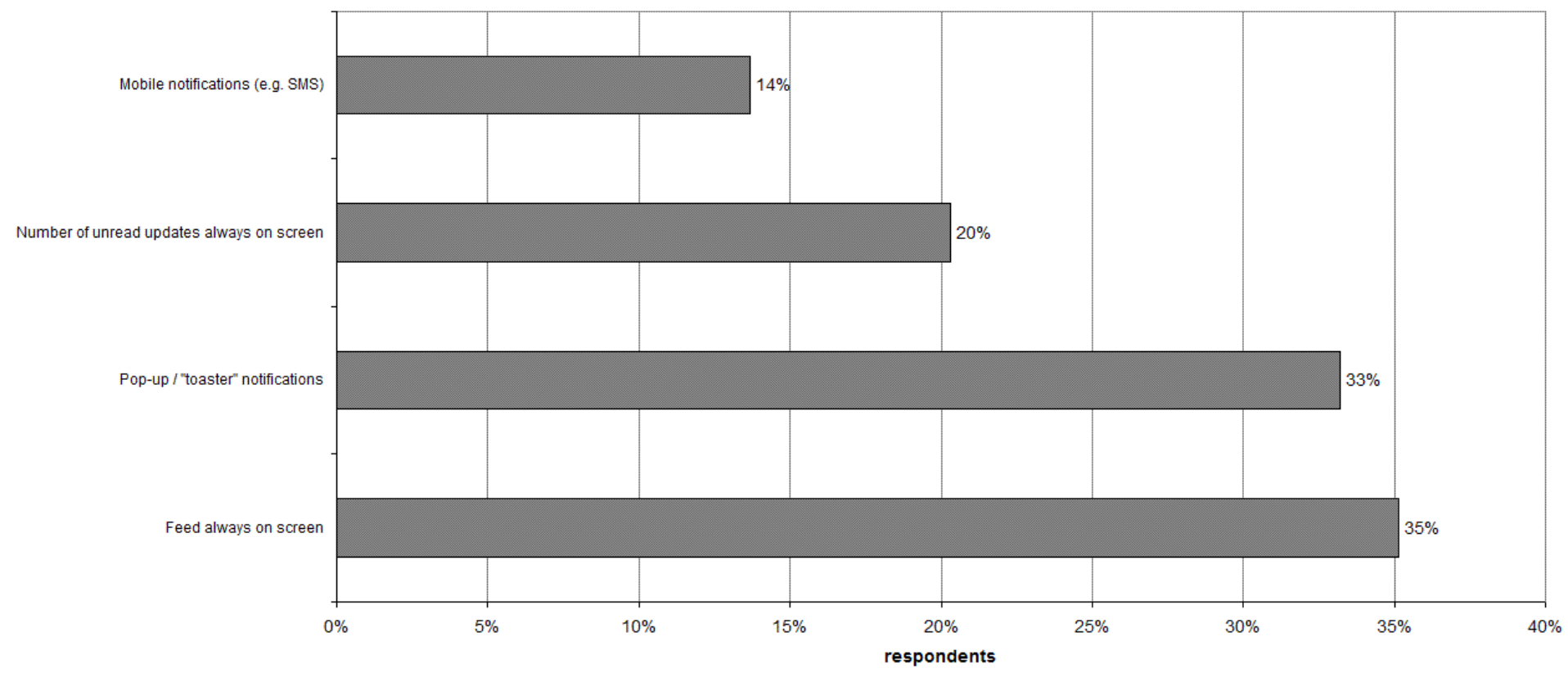

According to Figure 4, most respondents (35\%) keep the last updates from their microblogging platform always visible on their screen. About as many respondents (33\%) activated pop-up (also called toaster) notifications on their screen, in order to keep up with the last updates in real-time. Fewer respondents chose to monitor the number of unread updates $(20 \%)$, in order to decide when to read those messages, or to receive notifications on their mobile phone (e.g. SMS) (14\%).

Insert 5.gif Here, Caption = Attention given to notified updates 


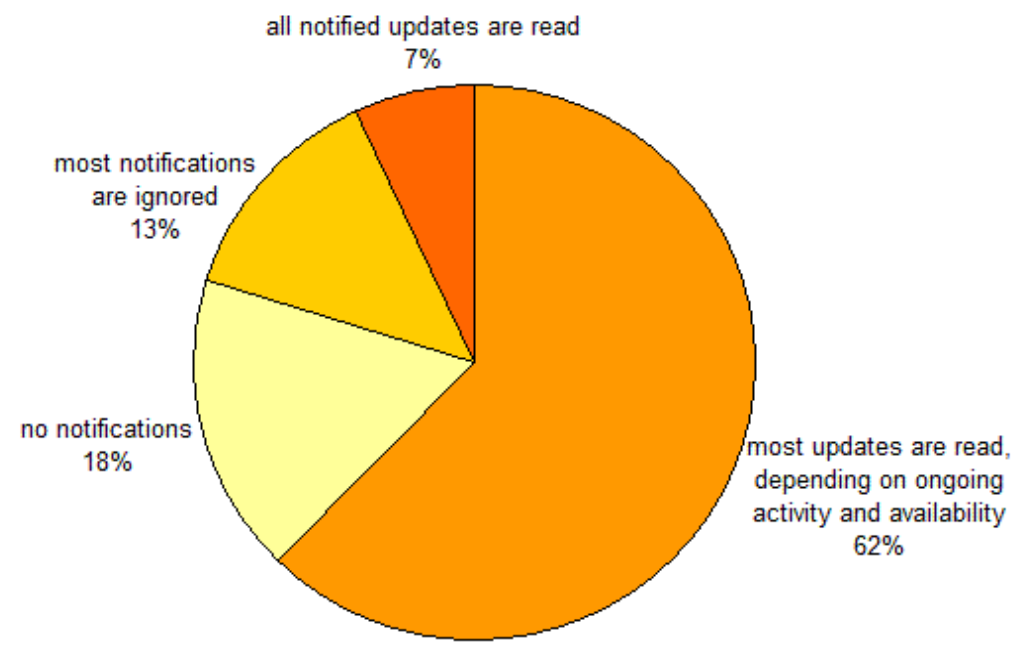

As seen on Figure 5, the amount of attention given to real-time update notifications varies among respondents who receive such notifications, whereas $18 \%$ of them do not receive such notifications. Most of them (62\%) read most notified updates, depending on their ongoing activity and availability. Others either read all notified updates (7\%), or simply ignore those (13\%).

Insert 6.gif Here, Caption = Probability of consulting content attached to updates (left), and of responding to them (right)
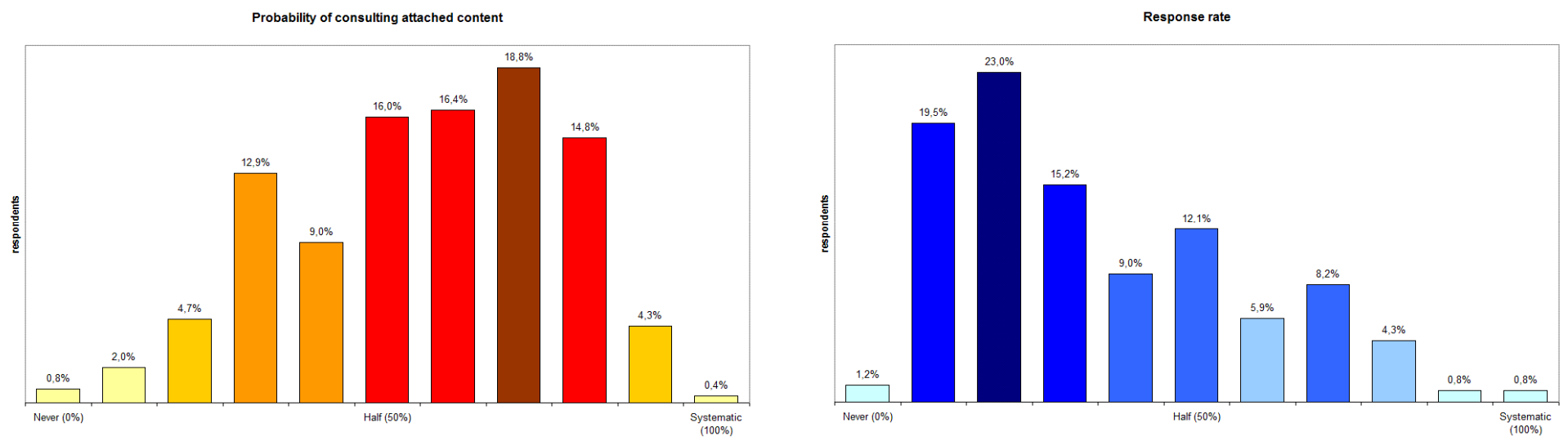
From Figure 6, we can observe that microbloggers consume more content than they produce. Indeed, $66 \%$ of them consult the attached content of $50 \%$ to $80 \%$ updates they receive, whereas the same proportion of respondents actually respond by replying or relaying $10 \%$ to $50 \%$ updates.

Insert 7.gif Here, Caption = Use of filtering

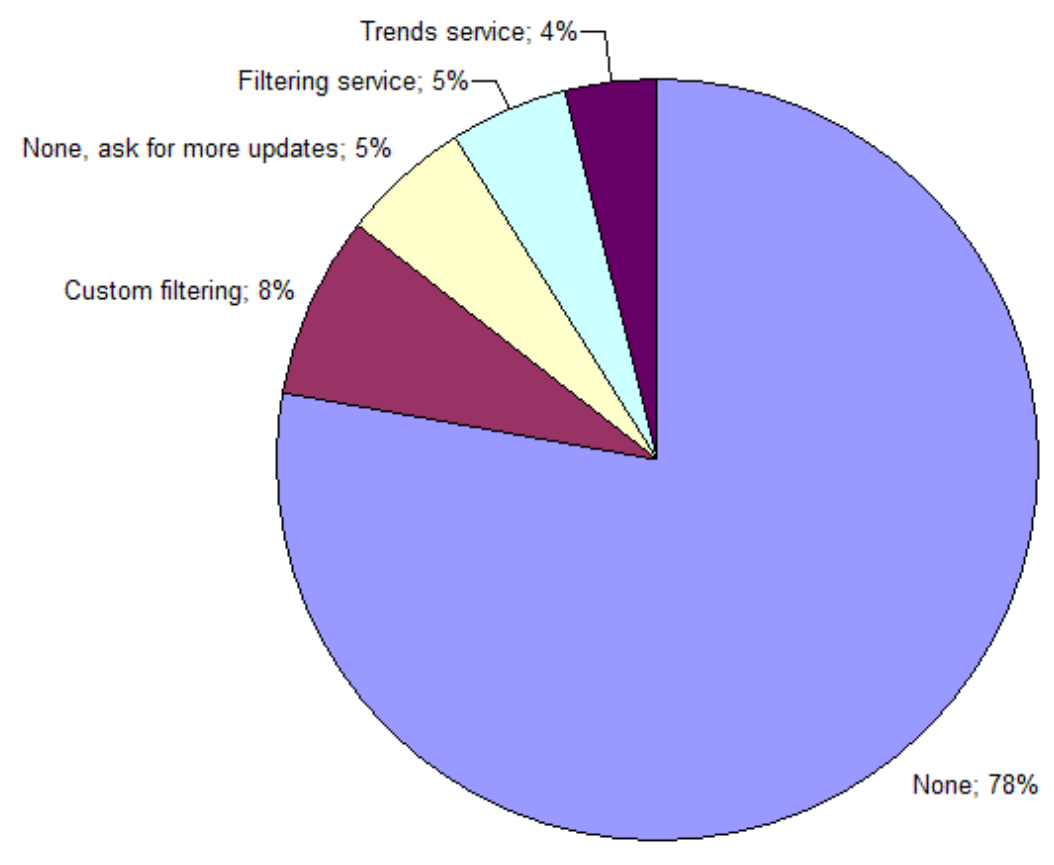

In response to the large amount of social updates they receive, Figure 7 depicts that $78 \%$ of respondents don't use filtering mechanisms. The most number of others who do (8\%) developed their own filtering mechanism, instead of leveraging existing services offering filters (5\%) or trends (4\%). $5 \%$ respondents, beyond not using filtering mechanisms, would rather receive more updates. This last category represents a close portion to respondents who follow less than 10 feeds, as depicted on Figure 1, which would explain their eagerness for more updates. 


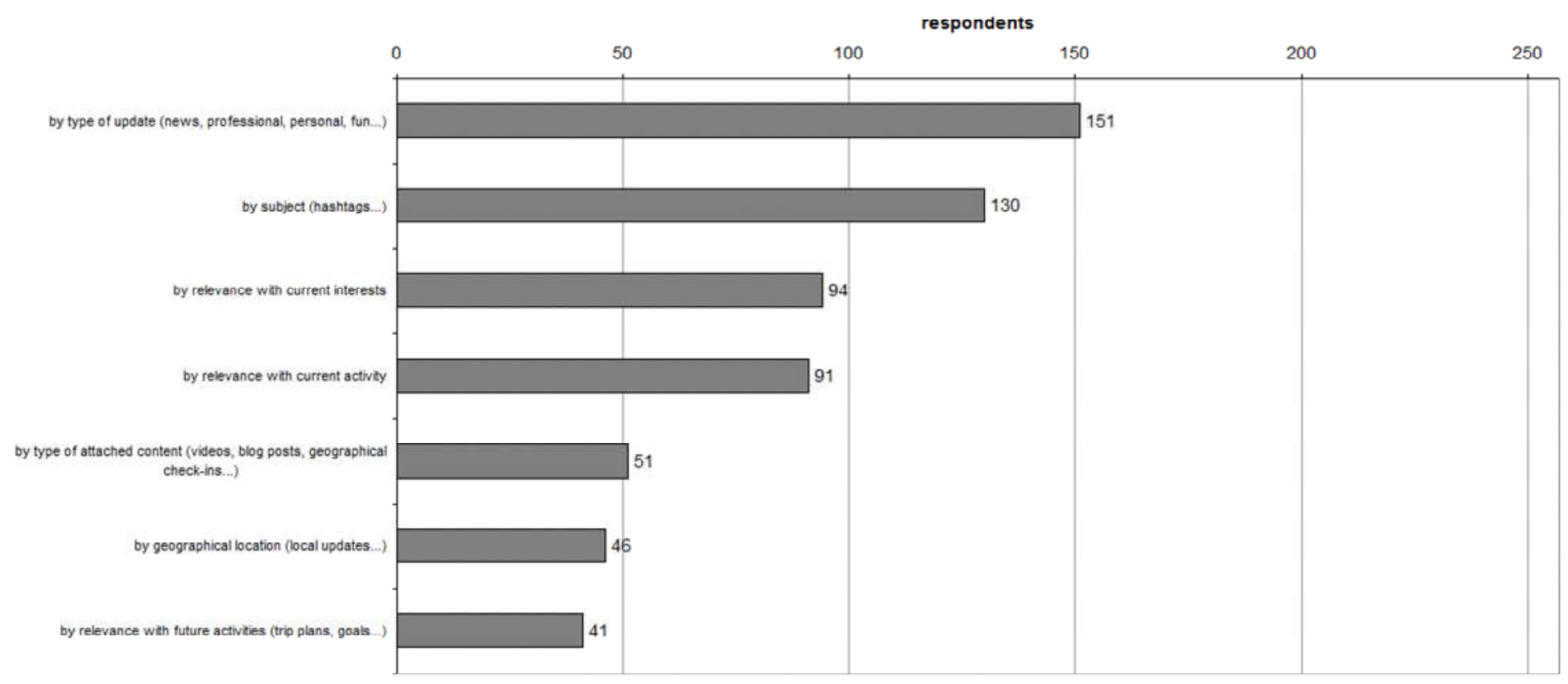

Although we have observed that most respondents don't use filtering mechanisms, Figure 8 reveals a need for filtering: $59 \%$ of them would like to filter by type of updates (e.g. news, professional, personal, fun, etc...) and $51 \%$ by subject. Relevance filtering is also expected by respondents, either according to their current interests (37\%) or current activity (36\%). Fewer of them would like to benefit from other filtering criteria on updates, such as the type of content (20\%), geographical proximity (18\%), or relevance with future activities and plans (16\%).

\section{Filtering mechanisms: challenges, solutions and opportunities}

On Figure 8, we have seen that the two most expected filtering mechanisms are by type of update, and by subject. This can be surprising, as it is already granted for microblogging users to choose whose feeds they follow, and to follow subjects of interest represented by corresponding terms and hashtags. However, these native features provided by current microblogging platforms are a partial solution to that problem: people do 
not always post updates of the same type (or at least, they do not have to), and it can be tedious for users to select the right terms and hashtags for following updates on a specific subject. Query enrichment and semantic search mechanisms could support them for this second need. Concerning the type of updates, a solution could be that people post updates through different feeds, depending on their type. They would thus have to expose and maintain separate professional, personal, and other specific feeds, and their followers would have to follow the feeds they are interested in, depending on the type of updates posted to those. Another solution would be to ask users to provide some metadata to describe the type of update they intend to post, as long as microblogging platforms would allow type-filtered subscriptions to their author's feed, instead of simply following his whole feed.

The two following most expected filtering mechanisms are more dynamic: they rely on relevance of updates with the consumer's current interests and activities. As a person's current interests can be profiled, updates can be ranked against this profile, in order to deliver the most relevant ones. Such filtering mechanism is proposed by the my6sense application (http://www.my6sense.com/), in which users' interests are profiled according to the content they actually read. Concerning the relevance with current activities, such profiling becomes more complex, as users can achieve their activities out of the scope of the application that delivers updates, e.g. on various computer applications, or even without the computer. In that case, some knowledge on the current activity of a user must be gathered by analyzing contextual cues acquired from several sensors: physical (e.g. user's location from a GPS device), virtual (e.g. name of the document being edited with word-processing software on the computer) and social (e.g. messages and updates from other users, giving clues about the user's current activity and context).

\section{Our proposal: contextual filtering of status updates}


In response to the need for more dynamic filtering, we have developed a system that relies on similarities between users' current contexts, for ranking the relevance of status updates received from followed people.

As defined in our last publication [joly_2010], a first prototype of our tag-based system, designed for computer-supported enterprises, extracts contextual information about users by analyzing the documents (e.g. web pages) they are currently reading. Users' context is represented by tags, crowd-sourced descriptions aggregated from several web services, including the Delicious social bookmarking service (http://www.delicious.com/) and SemanticProxy (http://semanticproxy.com/). When users share a status update, they can decide to attach their context, represented as a tag cloud that combines the content-based descriptions extracted from their documents. By doing so, the system recommends a few status updates from other users, which are the most relevant. In our case, relevance of status updates is evaluated according to the similarity between the last-known contexts of their authors. For a detailed description of the context model and its related processes, please refer to [joly_thesis].

Insert 9.jpg Here, Caption = Screenshot of the system's user interface: simultaneous points of view for two users. The user's current contextual tags are displayed dynamically on the top. The most relevant status updates (from other users) are listed below, according to the contextual tags attached to the user's last status update. 


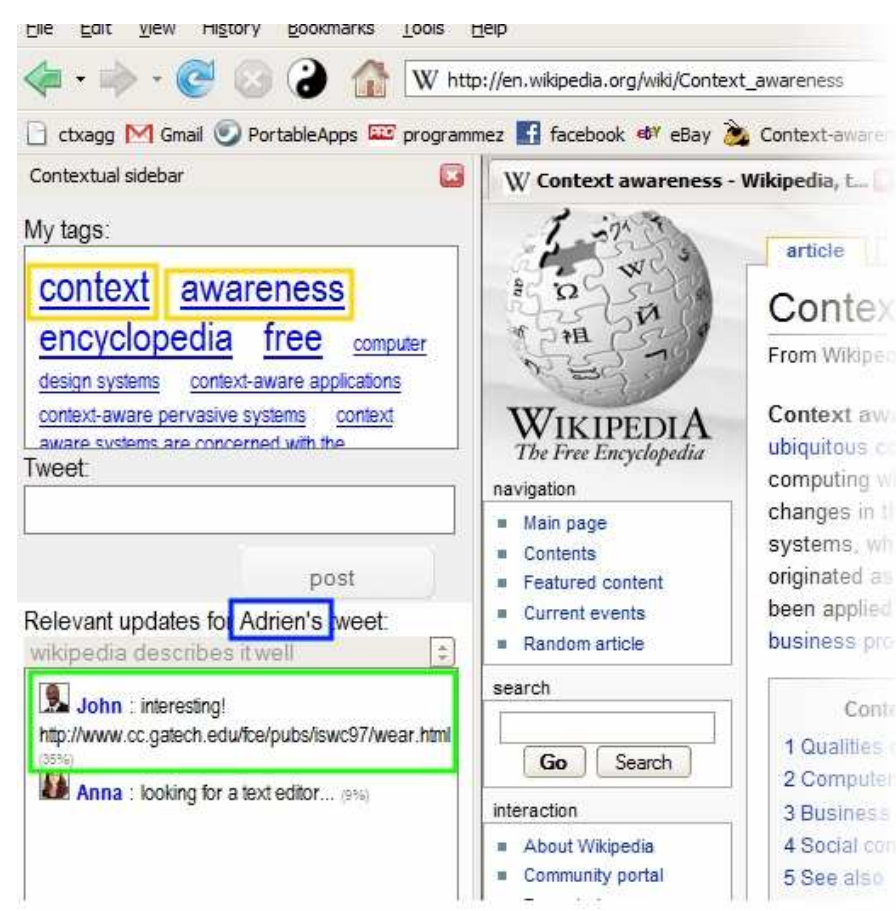

Adrien's browser

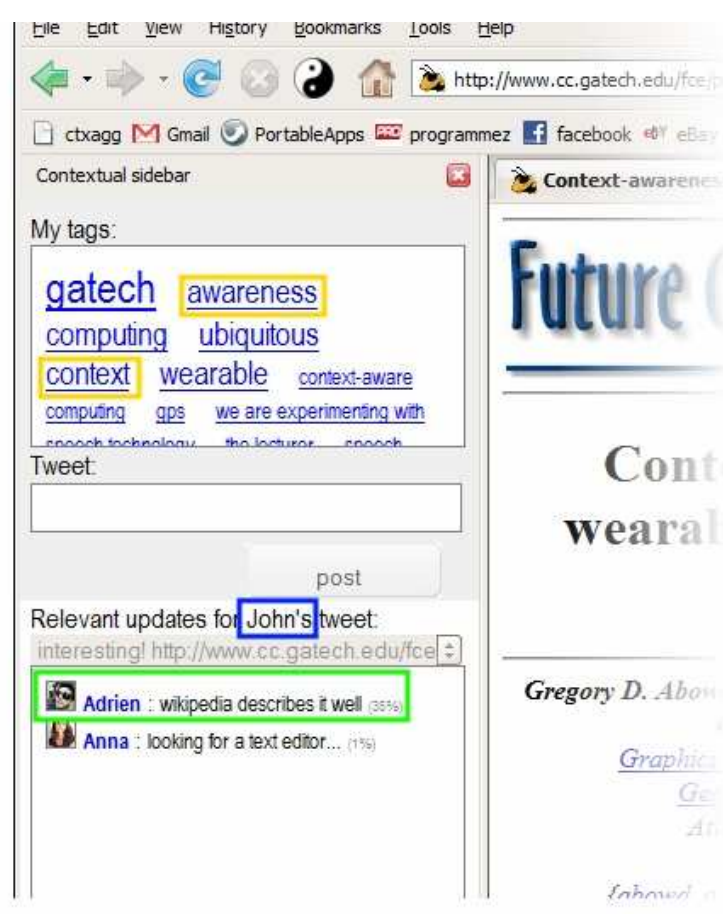

John's browser

On Figure 9, we present the simultaneous points of view of two users: Adrien and John. Adrien is browsing web pages about context-awareness, including the definition of this concept on Wikipedia. John is browsing web pages about ubiquitous computing, including a page from Georgia Tech (known as gatech). Their contextual tag clouds respectively represent the terms corresponding to these pages, and the most relevant status updates are displayed according to the contextual tag cloud attached to their last status update. On Adrien's screen, the first status update is from John, who provides the URL of an interesting web page, apparently about gatech. In gray, the relevance score of this status update is shown: $35 \%$. On John's screen, Adrien's last status update is displayed, also with a relevance score of $35 \%$. This score represents the similarity between Adrien's and John's last context. Here, they are similar because the terms context and awareness appear with a significant weight on both of them.

This prototype is functional and gives a good sense of the benefits of our approach: 
- users can quickly visualize and edit their own context before attaching it to their status updates;

- users' contexts are represented by meaningful tags, provided by humans;

- only status updates that are the most relevant to the user's current activity are displayed.

Therefore, social awareness is maintained, whereas information overload and interruptions are reduced.

\section{Conclusion}

The survey that we presented in this article reveals that users of real-time microblogging platforms (such as Twitter):

- usually consume many updates (with or without being notified in real-time), mostly for professional use, news and networking;

- mostly receive updates that are interesting in regard to their longer-term goals, more than to their current activities;

- consult the content attached to many updates, but do not respond to them often;

- and that they would benefit from filtering mechanisms.

In response to those observations, we proposed some opportunities for improvement:

- In order to allow users to filter updates by type more easily, we recommend that each user maintains separate accounts (with different followers) for each type of updates (e.g. personal messages, news on specific topics, etc...)

- New metadata could also be added to microblogging systems, so that authors could precise the type of each update they post. 
In response to the need for filtering by relevance with users' current interests and activities, we presented a system that can maintain a dynamic profile of users, based on computer-based context sensors and crowdsourced content descriptions.

\section{Acknowledgment}

The authors would like to thank the 256 respondents of the survey, for their participation and their encouragements

\section{About the authors}

Adrien JOLY received his PhD in Computer Science from the Institut National des Sciences Appliquées de Lyon (INSA-LYON, France) in 2010, under supervision of Pr. Pierre MARET. As member of the Social Communications department of Alcatel-Lucent Bell Labs France, in collaboration with CNRS-affiliated laboratories of University of Lyon (LIRIS / LaHC), his research covered Ambient Awareness and ContextAware Social Networks. Today, Adrien develops whyd, a new web-based search engine that leverages semantic and social knowledge.

Pierre MARET is a professor in Computer Sciences in the CNRS-LaHC Laboratory, University of Lyon in Saint Etienne, France. 
Johann DAIGREMONT is the head of the Social Communications department of Alcatel-Lucent Bell Labs France.

\section{References}

Java A., Song X., Finin T. \& Tseng B. (2007). "Why we twitter: understanding microblogging usage and communities." In Proceedings of the 9th WebKDD and 1st SNA-KDD 2007 workshop on Web mining and social network analysis, pp 56-65, ACM.

Mischaud E. (2007). "Twitter: Expressions of the Whole Self." MSc dissertation, London School of Economics and Political Science.

Dunbar R.I.M. (1993). "Co-evolution of neocortex size, group size and language in humans." Behavioral and brain sciences, 16, pp 681-735.

Roda C., Ach L., Morel B., Nabeth T., Angehrn A.A., Rudman P., Zajicek M., Kingma D., Molenaar I. \& Vanhala T. (2006). "AtGentive deliverable d1.2, state of the art report". Tech. Rep. D1.2, IST AtGentive.

Speier C., Vessey I. \& Valacich J.S. (2003). "The effects of interruptions, task complexity, and information presentation on computer-supported decision-making performance.” Decision Sciences, 34, pp 771-797.

Bailey B.P., Konstan J.A. \& Carlis J.V. (2001). "The effects of interruptions on task performance, annoyance, and anxiety in the user interface." In Proceedings of INTERACT, vol. 1, pp 593-601. 
Zijlstra F.R.H., Roe R.A., Leonora A.B. \& Krediet I. (1999). "Temporal factors in mental work: Effects of interrupted activities." Journal of Occupational and Organizational Psychology, 72, pp 163-185.

Franke J.L., Daniels J.J. \& McFarlane D.C. (2002). "Recovering context after interruption.” In Proceedings 24th Annual Meeting of the Cognitive Science Society (CogSci 2002), pp 310-315.

McFarlane D.C. \& Latorella K.A. (2002). "The scope and importance of human interruption in humancomputer interaction design." Human-Computer Interaction, 17, pp 1-61.

Nagata S.F. (2003). "Multitasking and interruptions during mobile web tasks." In Human Factors and Ergonomics Society Annual Meeting Proceedings, vol. 47, pp 1341-1345.

Gillie T. \& Broadbent D. (1989). "What makes interruptions disruptive? a study of length, similarity, and complexity." Psychological Research, 50, pp 243-250.

Miyata Y. \& Norman D.A. (1986). "Psychological issues in support of multiple activities." User centered system design, pp 265-284.

Joly A., Maret P., Daigremont J. (2010). "Contextual Recommendation of Social Updates, a Tag-based Framework." In Proceedings of the Active Media Technology 2010 conference (AMT 2010) / Lecture Notes in Computer Science, Springer. 
Joly A. "A Context Management Framework based on Wisdom of Crowds, for Social Awareness applications," PhD Thesis from Institut National des Sciences Appliquées de Lyon (INSA-LYON, France), 2010.

License: This work is licensed under a Creative Commons AttributionNonCommercial-NoDerivs 3.0 Unported License.

\section{(c) (1) $\Theta \Theta$

